\title{
Breast cancer arising within fibroadenoma: collective analysis of case reports in the literature and hints on treatment policy
}

Yu-Ting Wu ${ }^{1,2,3,4 \dagger}$, Shou-Tung Chen ${ }^{2,3 \dagger}$, Chih-Jung Chen ${ }^{5,6,7}$, Yao-Lung Kuo ${ }^{8,9}$, Ling-Ming Tseng ${ }^{10,11}$, Dar-Ren Chen ${ }^{1,2,3}$, Shou-Jen Kuo ${ }^{2,3}$ and Hung-Wen Lai ${ }^{1,2,3,11^{*}}$

\begin{abstract}
Background: Breast cancer arising within a fibroadenoma (BcaFad) is rare; the rate varies from $0.002 \%$ to $0.125 \%$ in fibroadenoma specimens. Owing to its rarity, the clinicopathologic feature and treatment principle of BcaFad is still not clear. Therefore, the aim of this study was to perform a collective analysis of case reports in the literature to identify the characteristics and optimal treatment for BcaFad.

Methods: We analyzed an aggregated sample of 30 patients with BcaFad from case reports in the literature $(n=24$ cases) and our present study ( $n=6$ cases). We collected and analyzed the clinicopathologic features and prognoses of patients with BcaFad, as well as treatments they received.

Results: The patients' mean age at diagnosis was 46.9 years. Twenty BcaFad patients (66.7\%) received breast-conserving surgery (BCS), and nine other patients (30.0\%) were treated with mastectomy. The rate of lymph node metastasis in BcaFad patients was $23.8 \%$. The breakdown of the histological types of BcaFad was invasive ductal carcinoma (53.3\%), followed by ductal carcinoma in situ (23.3\%), lobular carcinoma in situ (16.7\%) and invasive lobular carcinoma (13.3\%). More than half of patients with positive hormone receptor status received hormone therapy. Most BcaFad patients with lymph node metastases received chemotherapy, and 20.0\% of BcaFad patients treated with BCS received further radiotherapy. Only one patient had recurrence after surgery, and another had lung metastasis when diagnosed with BcaFad.
\end{abstract}

Conclusions: Most BcaFad patients could be managed by BCS. Adjuvant radiotherapy could be performed, but was not mandatory. Chemotherapy should be considered as a treatment option in the presence of lymph node metastasis.

Keywords: Breast cancer, Fibroadenoma, Hormone therapy, Radiotherapy

\section{Background}

Fibroadenoma is the most common cause of discrete breast lumps in young females [1,2] and occurs in $25 \%$ of asymptomatic women. Benign, asymptomatic fibroadenomas usually can be managed with nonoperative follow-up [3-5]. Symptomatic, progressively enlarging masses or atypical presentations, however, may warrant surgical excision.

\footnotetext{
* Correspondence: 143809@cch.org.tw

${ }^{\dagger}$ Equal contributors

'Endoscopic and Oncoplastic Breast Surgery Center, Comprehensive Breast Cancer Center, Changhua Christian Hospital, 135 Nanhsiao Street, Changhua City, Changhua County 500, Taiwan

${ }^{2}$ Division of General Surgery, Changhua Christian Hospital, 135 Nanhsiao Street, Changhua City, Changhua County 500, Taiwan

Full list of author information is available at the end of the article
}

Although very rare, breast cancer arising within fibroadenoma (BcaFad) can still be found. The incidence of BcaFad ranges from $0.125 \%$ to $0.02 \%$, according to different reports [6-8]. In such circumstances, carcinomas in situ (66.9\% lobular carcinoma in situ (LCIS) and $12.4 \%$ ductal carcinoma in situ (DCIS)) are found to be more common than invasive carcinomas $(11 \%$ invasive ductal carcinoma (IDC) and 3.4\% invasive lobular carcinoma (ILC)) [9]. The optimal management of patients with BcaFad is still not clear. Little information is available in current breast cancer management consensus guidelines [10-13]. It is unknown whether such patients should be treated similarly to those with breast cancer.

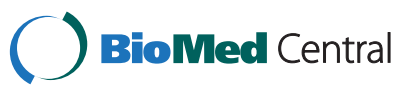

(C) 2014 Wu et al.; licensee BioMed Central Ltd. This is an Open Access article distributed under the terms of the Creative Commons Attribution License (http://creativecommons.org/licenses/by/4.0), which permits unrestricted use, distribution, and reproduction in any medium, provided the original work is properly credited. The Creative Commons Public Domain Dedication waiver (http://creativecommons.org/publicdomain/zero/1.0/) applies to the data made available in this article, unless otherwise stated. 
Owing to the rarity of BcaFad cases, clinicians in individual medical institutions have very little experience in treating these patients. Therefore, a collective case study is needed for more information about the optimal management of BcaFad. In this article, we present our experience with six BcaFad cases and used a systematic literature review process to find some characteristics of and hints for the optimal care of these patients.

\section{Methods}

To further elucidate the characteristics and optimal management of patients with BcaFad, we performed a collective analysis of case reports in the literature and our six cases. The literature review was performed through PubMed searches to collect English-language articles about BcaFad published between January 1986 and January 2013. The keywords used in the search use were "fibroadenoma", "carcinoma", "breast", "ductal" and "lobular".

The literature search was limited to studies focused on BcaFad with descriptions of diagnosis and/or treatment. The investigated parameters included age, gender, tumor size, diagnostic image, operation method, histology, hormone receptor status (including estrogen receptor (ER) and progesterone receptor (PR)), Human epidermal growth factor receptor 2 (HER2) status, chemotherapy and radiation therapy. The searches were limited to human studies. Articles were excluded if they did not present BcaFad, patient information or treatment details. Articles published in any language other than English were also excluded.

Demographic data collected and analyzed included age, gender, size of the primary lesion, duration of follow-up, image findings, fine-needle aspiration cytology or coreneedle biopsy results, pathology, operation method, postoperative therapy and recurrence or metastasis of the tumor.

\section{Results}

In our literature review, we collected 24 cases with detailed information from 21 English-language articles. After combining these with our 6 cases, the study population comprised 30 BcaFad patients (Figure 1 and Table 1). All of the patients were female, and their mean age at diagnosis was 46.9 years old (range, 27 to 80 years old). The mean duration from the finding of fibroadenoma to surgical excision was 61.2 months (range, 0.5 to 600 months). The mean tumor size of the fibroadenoma was $2.46 \mathrm{~cm}$ (range, 0.8 to $5.1 \mathrm{~cm}$ ). Most of the cancers found inside the breast fibroadenoma were in situ carcinoma or early breast cancer with minimal or small tumor size. The distribution of tumor locations was the right side $(53.3 \%)$, followed by the left side $(40.0 \%)$ and bilateral breast (3.3\%). The clinicopathologic data of these 30 patients are summarized in Table 1.

Twenty (66.7\%) of thirty patients with BcaFad received breast-conserving surgery (BCS), and nine other patients

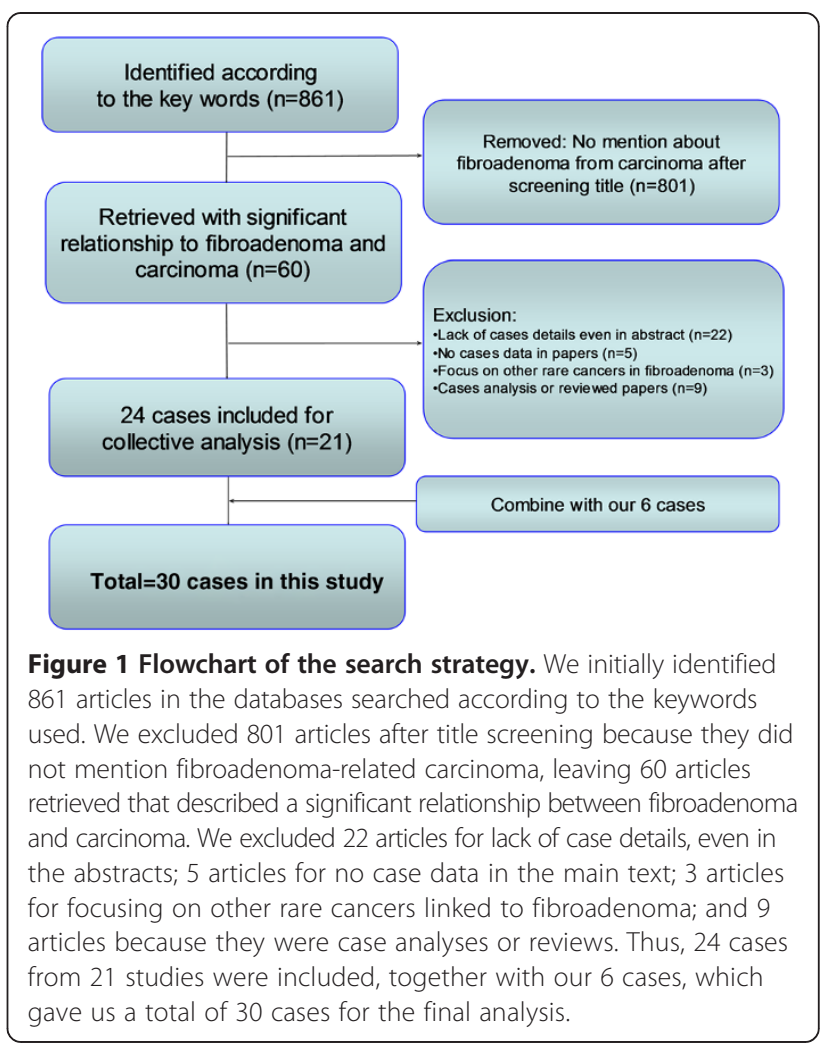

(30.0\%) received mastectomies. One (patient 26) of these nine mastectomy patients received immediate breast reconstruction (Figure 2). Furthermore, five (23.8\%) of twenty-one patients with the diagnosis of lymph node status had lymph node metastasis. Most patients were diagnosed with IDC (16 cases, $53.3 \%$ ), followed by DCIS (7 cases, 23.3\%), LCIS (5 cases, 16.7\%) and ILC (4 cases, 13.3\%) (Table 2). Among these patients, only one patient (patient 2) had both LCIS and IDC and another (patient 5) had both DCIS and LCIS. The TNM stages recorded were major in TisN0M0, T1aN0M0 stage to T1bN0M0. A T1aN1M0 tumor was also noted.

Regarding hormone receptor status and HER2 status, there were only 16 patients (53.3\%) with data mentioned about ER and PR status. Eleven (68.8\%) of these sixteen patients had ER + breast cancer, and ten patients (62.5\%) had PR + cancer. Of ten patients with known HER2 status, only one patient (10.0\%; patient 16 ) was found to have HER2-overexpressing breast cancer. Among 11 patients with hormone receptor-positive BcaFad, 6 patients $(54.5 \%)$ received tamoxifen treatment. Four $(80 \%)$ of five patients with lymph node metastasis received chemotherapy.

Nine patients were treated with mastectomy, and another twenty patients were treated with BCS. However, only four $(20.0 \%)$ of the twenty patients who underwent BCS received radiotherapy $[15,19,25]$. Patient 17 received radiotherapy to the chest wall following a mastectomy 
Table 1 Demographic data from identified studies in the literature and our cases ${ }^{a}$

\begin{tabular}{|c|c|c|c|c|c|c|c|c|c|c|c|c|c|c|}
\hline Patient & Study & $\begin{array}{l}\text { Age } \\
(\mathrm{yr})\end{array}$ & Tumor size $(\mathrm{cm})$ & $\begin{array}{l}\text { Noted tumor } \\
\text { duration (months) }\end{array}$ & Histology & $\begin{array}{l}\text { TNM } \\
\text { stage }\end{array}$ & Surgery & LN dissection & LN metastasis & $\begin{array}{l}\text { Receptor } \\
\text { status }\end{array}$ & $\mathrm{C} / \mathrm{T}$ & $H / T$ & $R / T$ & Outcome \\
\hline 1 & Kurosumi et al., 1994 [14] & 42 & $2 \times 3$ & 21 & IDC & & Ex & A & & & & & & \\
\hline 2 & Sarela et al., 1995 [15] & 56 & $2 \times 3$ & 2 & $\mathrm{LCIS}+\mathrm{IDC}$ & & MT & A & $P$ & & & & & \\
\hline 3 & Shah et al., 1999 [16] & 45 & $2.5 \times 2$ & 3 & LCIS & TisNOMO & Ex & & N & & & & & \\
\hline 4 & Yano et al., 2001 [17] & 54 & 2 & & ILC & TisNOMO & Ex & A & N & & & & & \\
\hline 5 & Kuijper et al., 2002 [18] & 46 & Multiple & & DCIS + LCIS & TisNOMO & MT & & & & & & & \\
\hline 6 & Abe et al., 2004 [19] & 42 & $5.1 \times 4.4$ & 60 & IDC & & MT & A & $P$ & ER-PR+ & Yes & Yes & No & \\
\hline 7 & Stafyla et al., 2004 [20] & 27 & 3.4 & & LCIS & TisNOMO & Ex & & $\mathrm{N}$ & & & & & \\
\hline 8 & Shin et al., 2006 [21] & 51 & $1.5 \times 1$ & 12 & IDC & & MT & S & $\mathrm{N}$ & ER+PR+ & & & & \\
\hline 9 & Yuen et al., 2007 [22] & 39 & 1.1 & & ILC & & BCS & & & & & & & \\
\hline 10 & Yuen et al., 2007 [22] & 45 & 0.8 & & ILC & & BCS & & & & & & & \\
\hline 11 & Borecky and Rickard, 2008 [23] & 64 & 1.2 & & IDC & T1bNOMO & $\mathrm{BCS}$ & S & $\mathrm{N}$ & ER+PR+ & & & & \\
\hline 12 & Borecky and Rickard, 2008 [23] & 80 & 4.5 & 600 & IDC & & BCS & s & N & & & & & \\
\hline 13 & Borecky and Rickard, 2008 [23] & 53 & 1.7 & 12 & DCIS & TisNOMO & Ex & S & N & & & & & \\
\hline \multirow[t]{2}{*}{14} & Gashi-Luci et al., 2009 [24] & 39 & $2.6 \times 1.6$ & & IDC & & MT & A & $\mathrm{N}$ & ER-PR- & & & & $\mathrm{R}$ \\
\hline & & & & & & & & & & HER2- & & & & \\
\hline \multirow[t]{2}{*}{15} & Khandelwal et al., 2009 [25] & 35 & $2 \times 3$ & 2 & IDC & & BCS & A & $P$ & ER+PR+ & Yes & Yes & Yes & \\
\hline & & & & & & & & & & HER2- & & & & \\
\hline \multirow[t]{2}{*}{16} & lyengar et al., 2009 [26] & 43 & 1.8 & 24 & IDC & & MT & & & ER-PR- & & & & \\
\hline & & & & & & & & & & HER2+ & & & & \\
\hline \multirow[t]{2}{*}{17} & Rao et al., 2010 [27] & 30 & $4 \times 2$ & 1 & IDC & & MT & A & $P$ & ER-PR- & Yes & No & Yes & \\
\hline & & & & & & & & & & HER2- & & & & \\
\hline \multirow[t]{2}{*}{18} & Petersson et al., 2010 [28] & 49 & 3 & 48 & IDC & & Ex & S & N & $E R+P R+$ & & & & \\
\hline & & & & & & & & & & HER2- & & & & \\
\hline 19 & Kato et al., 2011 [29] & 42 & 1.5 & & DCIS & TisNOMO & BCS & S & $\mathrm{N}$ & & & & & \\
\hline 20 & Ooe et al., 2011 [30] & 46 & $2.4 \times 1.7$ & 60 & DCIS & TisNOMO & BCS & S & $\mathrm{N}$ & ER+PR+ & No & Yes & Yes & \\
\hline \multirow[t]{2}{*}{21} & Tajima et al., 2011 [31] & 60 & $1.9 \times 1.6$ & 3 & ILC & & BCS & & & ER+PR+ & & & & \\
\hline & & & & & & & & & & HER2- & & & & \\
\hline 22 & Abu-Rahmeh et al., 2012 [32] & 69 & 5 & 180 & IDC & & & & & & & & & $\begin{array}{l}\text { Lung } \\
\text { metastasis }^{\mathrm{b}}\end{array}$ \\
\hline 23 & Jahan et al., 2012 [33] & 55 & $5 \times 4 \times 3$ & 240 & IDC & & MT & & & & & & & \\
\hline 24 & Butler et al., 2012 [34] & 46 & $0.8 \times 0.8$ & & ILC & T1bNOMO & Ex & & & & & & & \\
\hline
\end{tabular}


Table 1 Demographic data from identified studies in the literature and our cases ${ }^{\mathrm{a}}$ (Continued)

\begin{tabular}{|c|c|c|c|c|c|c|c|c|c|c|c|c|c|}
\hline 25 & Present study & 39 & $2.7 \times 2.7$ & 24 & IDC & T1aNOMO & $\mathrm{BCS}$ & S & $\mathrm{N}$ & $\begin{array}{l}\text { ER+PR+ } \\
\text { HER2- }\end{array}$ & No & $\mathrm{Nr}$ & $\mathrm{Nr}$ \\
\hline 26 & Present study & 31 & $3.5 \times 3.4$ & 84 & IDC & T1aN1M0 & MT & A & P & $\begin{array}{l}\text { ER+PR+ } \\
\text { HER2- }\end{array}$ & Yes & Yes & No \\
\hline 27 & Present study & 30 & $1.5 \times 1.4$ & & DCIS & TisNOMO & $\mathrm{BCS}$ & & & $\begin{array}{l}\text { ER+PR+ } \\
\text { HER2- }\end{array}$ & No & Yes & No \\
\hline 28 & Present study & 63 & 1.2 & 0.5 & DCIS & TisNOMO & $\mathrm{BCS}$ & S & $\mathrm{N}$ & $\begin{array}{l}\text { ER+PR+ } \\
\text { HER2- }\end{array}$ & No & Yes & Yes \\
\hline 29 & Present study & 48 & 0.9 & 3 & DCIS & TisNOMO & Ex & $S$ & $\mathrm{~N}$ & & No & No & No \\
\hline 30 & Present study & 40 & 0.6 & 0 & IDC & T1bNOMO & MT & S & $\mathrm{N}$ & $\mathrm{ER}+\mathrm{PR}-$ & No & Yes & No \\
\hline
\end{tabular}

${ }^{\mathrm{a} A}$, Axillary lymph node dissection level I/II/III; B, Benign; C/T, Chemotherapy; ER, Estrogen receptor; Ex, Excision; HER2, Human epidermal growth factor receptor 2 ; H/T, Hormone therapy; LN, Lymph node; $\mathrm{M}$,

Malignancy; MT, Mastectomy; N, Negative; Nr, Patient refuse; P, Positive; PR, Progesterone receptor; R, Recurrence; R/T, Radiotherapy; S, Sentinel lymph node dissection; TNM, Tumor, node, metastasis. ${ }^{b}$ Lung metastasis at diagnosis. 


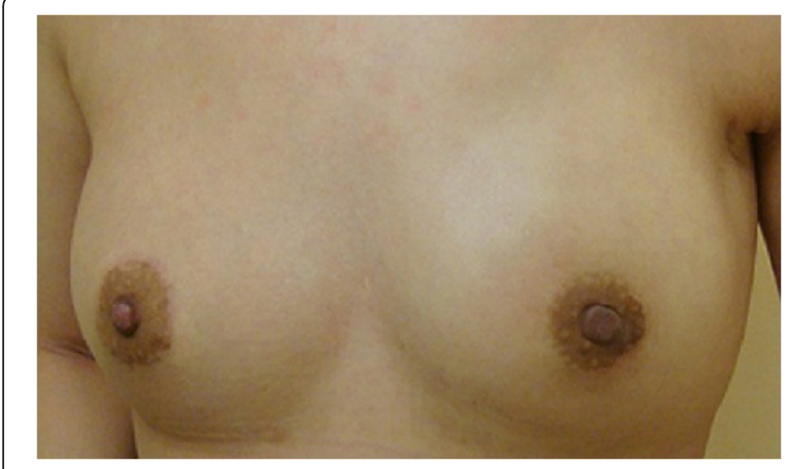

Figure 2 Postoperative photograph of patient 26. This patient had centrally located breast cancer arising from a fibroadenoma diagnosed before surgery. She was treated with endoscopically assisted nipple-sparing mastectomy combined with immediate breast reconstruction with a gel implant. Photograph was taken 3 months after surgery.

performed for lymph node metastasis [27]. Of the four BCS patients with IDC, only one (25.0\%) received radiation therapy. In addition, among six BCS patients with DCIS, only two (33.3\%) received radiotherapy. Of fifteen patients with descriptions of outcome and distant metastasis, only one (patient 22) was found to have lung metastasis at diagnosis. Another patient (patient 14) had a local recurrence 5 months after surgery.

\section{Discussion}

It is very unusual for a carcinoma of the breast to arise within a fibroadenoma. In this report, we present our 6 cases together with 24 previously reported cases for a collective case analysis. Among these 30 cases, the mean age at diagnosis of BcaFad was 46.9 years, which was older than that at diagnosis of benign fibroadenoma (age range from $20 \mathrm{~s}$ to $30 \mathrm{~s}$ ) [5,35]. The mean duration from finding a fibroadenoma to surgical excision was 61.2 months (range from 0.5 to 600 months). This long duration can be explained by the large size of the breast tumors (mean $2.46 \mathrm{~cm}$ ) in this group of patients. This tumor size refers to the diameter of the fibroadenoma in which the malignant component was identified. In our present study, most BcaFads were predominantly found to be small cancers in relatively large fibroadenomas. However, the tumor size was not reported in most of the reviews we included, so we could not present the actual pathologic tumor size in each individual (Tables 1 and 2). Half of the data did not contain details regarding TNM stage; the other half were for stages TisNOM0, T1aNOM0, T1bN0M0 and T1aN1M0. However, we could assume that most of the limited data were for early breast cancer according to the descriptions of histology.

According to our collective case analysis, the major histological type of BcaFad was IDC (53.3\%), followed by DCIS (23.3\%), LCIS (16.7\%) and ILC (13.3\%) (Table 2).
Table 2 Demographic and clinical features ${ }^{a}$

\begin{tabular}{|c|c|}
\hline Characteristics $(N=30)$ & Data \\
\hline Mean age (range), yr & 46.9 (27 to 80$)$ \\
\hline Mean tumor size (range), $\mathrm{cm}$ & $2.46(0.8$ to 5.1$)$ \\
\hline Female gender, $n(\%)$ & $30(100 \%)$ \\
\hline Mean tumor follow-up duration (range) months & $61.2(0.5$ to 600$)$ \\
\hline \multicolumn{2}{|l|}{ Histology $(N=30), n(\%)$} \\
\hline DCIS & $7(23.3 \%)$ \\
\hline LCIS & $5(16.7 \%)$ \\
\hline IDC & $16(53.3 \%)$ \\
\hline ILC & $4(13.3 \%)$ \\
\hline \multicolumn{2}{|l|}{ TNM stage $(N=30), n(\%)$} \\
\hline TisN0M0 & $10(33.3 \%)$ \\
\hline T1aNOMO & $1(3.3 \%)$ \\
\hline T1bNOMO & $3(10.0 \%)$ \\
\hline T1aN1M0 & $1(3.3 \%)$ \\
\hline Unclear & $15(30 \%)$ \\
\hline \multicolumn{2}{|l|}{ Operation method $(N=30), n(\%)$} \\
\hline $\mathrm{BCS}$ & $20(66.7 \%)$ \\
\hline Mastectomy & $9(30.0 \%)$ \\
\hline No data & $1(3.3 \%)$ \\
\hline \multicolumn{2}{|l|}{ Lymph node dissection $(N=30), n(\%)$} \\
\hline Axillary clearance & $8(26.7 \%)$ \\
\hline Sentinel lymph node dissection & $11(36.7 \%)$ \\
\hline Not done & $1(3.3 \%)$ \\
\hline No data & $10(33.3 \%)$ \\
\hline \multicolumn{2}{|l|}{ Lymph node $(N=30), n(\%)$} \\
\hline Metastasis & $5(16.7 \%)$ \\
\hline Negative & $16(53.3 \%)$ \\
\hline No data & $9(30.0 \%)$ \\
\hline \multicolumn{2}{|l|}{ Receptor status } \\
\hline $\mathrm{ER}+(n=16)$ & $11(68.8 \%)$ \\
\hline $\mathrm{PR}+(n=16)$ & $10(62.5 \%)$ \\
\hline HER2+ $(n=10)$ & $1(10.0 \%)$ \\
\hline \multicolumn{2}{|l|}{ Further management } \\
\hline Chemotherapy $(n=10)$ & $4(40.0 \%)$ \\
\hline Hormone therapy $(n=10)$ & $6(60.0 \%)$ \\
\hline Radiation therapy $(n=11)$ & $5(45.5 \%)$ \\
\hline \multicolumn{2}{|l|}{ Outcome } \\
\hline Average follow-up (range), months & 21.9 (5 to 59$)$ \\
\hline Recurrence $(n=16)$ & $1(6.3 \%)$ \\
\hline Distant metastasis ${ }^{\complement}(n=16)$ & $1(6.3 \%)$ \\
\hline
\end{tabular}

${ }^{\mathrm{a} B C S}$, Breast-conserving surgery; DCIS, Ductal carcinoma in situ; ER, Estrogen receptor; HER2, Human epidermal growth factor receptor 2; IDC, Invasive ductal carcinoma; ILC, Invasive lobular carcinoma; LCIS, Lobular carcinoma in situ; PR, Progesterone receptor; TNM, Tumor, node, metastasis. ${ }^{\mathrm{b}}$ One patient had both LCIS and IDC, and another had both DCIS and LCIS. 'Distant metastasis was noted at cancer diagnosis. 
These findings are not consistent with previous reports that BcaFads were mainly carcinomas in situ $(66.9 \%$ LCIS and $12.4 \%$ DCIS), followed by invasive carcinoma (11\% IDC and 3.4\% ILC) [9]. This discrepancy might be due to selection bias. Our present study is a collective analysis of case reports in the literature. Patients with invasive carcinoma inside fibroadenoma are rare and tend to be presented as case reports. In our six cases, the cancerous parts of the tumors were limited within the capsule of the underlying fibroadenoma without extension to peripheral breast tissue. In those BcaFad with DCIS, the DCIS was limited inside the fibroadenoma without invasion into the adjacent nonfibroadenoma breast tissue. In the LCIScontaining tumors, three patients had pure LCIS, one patient had both IDC and LCIS and two patients had both ILC and LCIS. None of them were found to have bilateral breast cancer. In our present analysis, we found that LCIS may be associated with invasive breast cancer.

In this study, $20(66.7 \%)$ of 30 patients with BcaFad could be managed by BCS, and another 9 patients (30.0\%) received mastectomies. The treatment principle for benign fibroadenomas is surgical excision with a thin ring of benign breast tissue [5], and breast conservation is usually feasible. BcaFad is usually found incidentally during the pathologic check when the breast tumor is being excised. This could explain why most of these patients (66.7\%) received BCS as their surgical treatment. This breast-conserving rate is compatible with the reported data (19.6-58.0\%) in the management of breast cancer with the same tumor size in the NASBP B-06 trial (National Surgical Adjuvant Breast and Bowel Project) and the National Cancer Database in the United States [36,37].

Another reason for the high breast-conserving rate of the patients in this group is that most fibroadenomas are well-defined, with a "capsule" [2,5]. If the initial resection margin is free of cancer or only LCIS is inside the fibroadenoma, then a tumorectomy or lumpectomy alone may be sufficient $[15,25,38]$. These facts could explain why the high rate of patients with BcaFad received BCS in this study. If the resection margin is involved or close, however, then a further wide excision may be needed [7].

Mastectomy (30.0\% in this study) may still be needed in some circumstances-usually in large, multifocal or central located tumor [39]. One of our six patients (patient 26) received an endoscopically assisted, nipple-sparing mastectomy combined with immediate breast reconstruction using a gel implant because of the large size and central location of the breast tumor (Figure 2). Owing to the favorable prognosis, mastectomy with immediate breast reconstruction can be considered in patients with BcaFad when a mastectomy is needed.

Radiotherapy can effectively reduce local recurrence, and this reduction in disease relapse may translate to prolonged overall survival $[11,12,40]$. Nowadays, there is an established rule that, in order to decrease the risk of local recurrence, radiotherapy should be delivered to breast cancer patients receiving BCS $[10,13]$. Should patients with BcaFad have to receive radiotherapy after partial mastectomy? Tiu et al. [41] stated that BcaFad behaves like breast cancer at the same stage and that therefore the treatment should follow the same modality. However, only four $(20.0 \%)$ of the BCS patients received radiotherapy according to our collective case analysis $[15,19,25]$. Of four BCS patients with IDC, only one patient (25.0\%; patient 15) received radiation therapy. In addition, among six BCS patients with DCIS, only two (33.3\%) received radiotherapy.

According to our collective case analysis in this study, it seemed as though not all surgeons agreed that radiotherapy should be delivered to patients with BcaFad after BCS. To date, to our knowledge, no randomized controlled trials or large cohort studies have been conducted to answer this question. According to our literature review (Figure 1), fewer than 250 patients with BcaFad have been reported to date, and only 8 of them were reported to have received radiotherapy $[14,19,25,27,30]$. Whether radiotherapy is necessary for BcaFad patients after BCS is still unknown; more solid evidence is needed to establish the role of radiotherapy for this particular group of patients. To the best of our knowledge, radiotherapy seems optional rather than mandatory for BcaFad patients after partial mastectomy.

Owing to the limitations of a literature review, hormonal and HER2 receptor status was incompletely reported. In our collective case analysis, the incidence of hormone receptor-positive BcaFad was $68.8 \% \mathrm{ER}+$ and $62.5 \% \mathrm{PR}+$, which is compatible with of the incidence in common types of breast cancer (range, approximately $60 \%$ to $90 \%$ ) $[42,43]$. However, the rate of HER2 overexpression was only $10.0 \%$, which is a little lower than that of common types of breast cancer (approximately 15\% to 25\%) [44-46].

According to reports in the literature, most BcaFad cases are carcinoma in situ (79.3\%), and less than 15\% are invasive carcinomas [9]. BcaFad with lymph node metastasis is unusual, but can still occur $[15,19,25,27,47,48]$. A sentinel lymph node biopsy should be performed if there is a pathologic confirmation of the presence of invasive carcinoma of BcaFad. Furthermore, axillary lymph node dissection should be performed in the presence of lymph node metastasis. Lymph node metastasis, rather than tumor size or hormone status, is the main concern underlying the use of chemotherapy for patients with BcaFad $[19,25,27,49]$.

The prognosis for patients with BcaFad was reported to be more favorable than that in other common types of breast cancer $[19,25]$. In our collective case analysis, 
among 15 patients with descriptions of long-term results, 1 patient (6.67\%, patient 14) had local recurrence 5 months after surgery [24] and another (patient 22) was found to have lung metastasis [32] when diagnosed with BcaFad. Death caused by BcaFad was uncommon, but still can occur in cases of invasive carcinomas at a late stage $[50,51]$.

\section{Conclusions}

BcaFad is an infrequent malignancy and carries a favorable prognosis. Most BcaFads can be managed with $\mathrm{BCS}$, and radiotherapy can be delivered optionally even when patient has undergone BCS. A sentinel lymph node biopsy should be performed if invasive carcinoma is present. In the presence of lymph node metastasis, chemotherapy should be considered to prevent distant metastasis.

\section{Abbreviations \\ BcaFad: Breast cancer arising within fibroadenoma; BCS: Breast-conserving surgery; DCIS: Ductal carcinoma in situ; ER: Estrogen receptor; IDC: Invasive ductal carcinoma; HER2: Human epidermal growth factor receptor 2; \\ ILC: Invasive lobular carcinoma; LCIS: Lobular carcinoma in situ; PR: Progesterone receptor.}

\section{Competing interests}

The authors declare that they have no competing interests.

\section{Authors' contributions}

HWL, STC and YTW designed the study. YTW, STC, YLK, LMT and CJC collected data. YTW, HWL, YLK and CJC prepared the manuscript. DRC, SJK and LMJ revised the manuscript. All authors read and approved the final manuscript.

\section{Authors' information}

YTW, STC, DRC, SJK and HWL: Comprehensive Breast Cancer Center, Changhua Christian Hospital, Changhua, Taiwan. YTW: Department of Surgery, Sinying Hospital, Ministry of Health and Welfare, Tainan, Taiwan. CJC: Department of Surgical Pathology, Changhua Christian Hospital, Changhua, Taiwan. YLK: Department of Surgery, National Cheng-Kung University Hospital, Tainan, Taiwan. LMT: Department of Surgery, Taipei Veterans General Hospital, Taipei, Taiwan.

\section{Acknowledgments}

This study was supported by the research program at Changhua Christian Hospital. The authors thank the research nurse specialists of Changhua Christian Hospital, National Cheng-Kung University Hospital and Taipei Veterans General Hospital.

\section{Author details}

${ }^{1}$ Endoscopic and Oncoplastic Breast Surgery Center, Comprehensive Breast Cancer Center, Changhua Christian Hospital, 135 Nanhsiao Street, Changhua City, Changhua County 500, Taiwan. ${ }^{2}$ Division of General Surgery, Changhua Christian Hospital, 135 Nanhsiao Street, Changhua City, Changhua County 500, Taiwan. ${ }^{3}$ Department of Surgery, Comprehensive Breast Cancer Center, Changhua Christian Hospital, 135 Nanhsiao Street, Changhua City, Changhua County 500, Taiwan. ${ }^{4}$ Department of Surgery, Sinying Hospital, Ministry of Health and Welfare, 73 Xinyi Street, Xinying Dist., Tainan City 730, Taiwan. ${ }^{5}$ Department of Surgical Pathology, Changhua Christian Hospital, 135 Nanhsiao Street, Changhua City, Changhua County 500, Taiwan. ${ }^{6}$ School of Medicine, Chung Shan Medical University, Taichung, No. 110, Sec. 1, Jianguo N. Rd., Taichung City 40201, Taiwan. ${ }^{7}$ Department of Medical Technology, Jen-Teh Junior College of Medicine, Nursing and Management, No 79-9, Sha-Luen Hu, Xi-Zhou Li, Hou-Loung Town, Miaoli County, Taiwan. ${ }^{8}$ Division of General Surgery, Department of Surgery, National Cheng-Kung University Hospital, Tainan and Dou-Liou branches, No.138, Sheng Li Road, Tainan 704, Taiwan and No.345, Zhuangjing Rd., Douliu City, Yunlin County 64043, Taiwan. ${ }^{9}$ Division of Plastic and Reconstructive Surgery, Department of
Surgery, National Cheng-Kung University Hospital, Tainan and Dou-Liou branches, No.138, Sheng Li Road, Tainan 704, Taiwan and No.345, Zhuangjing Rd., Douliu City, Yunlin County 64043, Taiwan. ${ }^{10}$ Division of General Surgery, Department of Surgery, Taipei Veterans General Hospital, No.201, Sec. 2, Shipai Rd., Beitou District, Taipei City 11217, Taiwan. ${ }^{11}$ School of Medicine, National Yang Ming University, Taipei, No.155, Sec.2, Linong Street, Taipei 112, Taiwan.

Received: 3 April 2014 Accepted: 25 September 2014 Published: 10 November 2014

\section{References}

1. Carty NJ, Carter C, Rubin C, Ravichandran D, Royle GT, Taylor I: Management of fibroadenoma of the breast. Ann R Coll Surg Engl 1995, 77:127-130.

2. Foster ME, Garrahan N, Williams S: Fibroadenoma of the breast: a clinical and pathological study. J R Coll Surg Edinb 1988, 33:16-19.

3. Cant PJ, Madden MV, Coleman MG, Dent DM: Non-operative management of breast masses diagnosed as fibroadenoma. Br J Surg 1995, 82:792-794.

4. Gordon PB, Gagnon FA, Lanzkowsky L: Solid breast masses diagnosed as fibroadenoma at fine-needle aspiration biopsy: acceptable rates of growth at long-term follow-up. Radiology 2003, 229:233-238.

5. Greenberg R, Skornick Y, Kaplan O: Management of breast fibroadenomas. J Gen Intern Med 1998, 13:640-645.

6. Deschênes L, Jacob S, Fabia J, Christen A: Beware of breast fibroadenomas in middle-aged women. Can J Surg 1985, 28:372-374.

7. Dupont WD, Page DL, Parl FF, Vnencak-Jones CL, Plummer WD Jr, Rados MS, Schuyler PA: Long-term risk of breast cancer in women with fibroadenoma. N Engl J Med 1994, 331:10-15.

8. Buzanowski-Konakry K, Harrison EG Jr, Payne WS: Lobular carcinoma arising in fibroadenoma of the breast. Cancer 1975, 35:450-456.

9. Fukuda M, Nagao K, Nishimura R, Matsuda M, Baba K, Ueno Y, Morinaga H, Omachi H, Hamada T: Carcinoma arising in fibroadenoma of the breast-a case report and review of the literature. Jpn J Surg 1989, 19:593-596.

10. Goldhirsch A, Wood WC, Coates AS, Gelber RD, Thürlimann B, Senn HJ Panel members: Strategies for subtypes-dealing with the diversity of breast cancer: highlights of the St. Gallen International Expert Consensus on the Primary Therapy of Early Breast Cancer 2011. Ann Oncol 2011, 22:1736-1747.

11. Early Breast Cancer Trialists' Collaborative Group (EBCTCG): Effects of radiotherapy and of differences in the extent of surgery for early breast cancer on local recurrence and 15-year survival: an overview of the randomised trials. Lancet 2005, 366:2087-2106.

12. Early Breast Cancer Trialists' Collaborative Group (EBCTCG): Effect of radiotherapy after breast-conserving surgery on 10-year recurrence and 15-year breast cancer death: meta-analysis of individual patient data for 10,801 women in 17 randomised trials. Lancet 2011, 378:1707-1716.

13. Theriault RL, Carlson RW, Allred C, Anderson BO, Burstein HJ, Edge SB, Farrar WB, Forero A, Giordano SH, Goldstein LJ, Gradishar WJ, Hayes DF, Hudis CA, Isakoff SJ, Ljung BME, Mankoff DA, Marcom PK, Mayer IA, McCormick B, Pierce LJ, Reed EC, Schwartzberg LS, Smith ML, Soliman H, Somlo G, Ward $\mathrm{JH}$, Wolff AC, Zellars R, Shead DA, Kumar R, National Comprehensive Cancer Network: NCCN Guidelines Insights: Breast cancer, version 3.2013: featured updates to the NCCN guidelines. J Natl Compr Canc Netw 2013, 11:753-761. [https://www.nccn.org/store/login/login.aspx?ReturnURL=http:// www.nccn.org/professionals/physician_gls/pdf/breast.pdf] (accessed 30 September 2014).

14. Kurosumi M, Itokazu R, Mamiya Y, Kishi K, Takayama S, Nagasawa M, Kurihara T, Suemasu K, Higashi Y: Invasive ductal carcinoma with a predominant intraductal component arising in a fibroadenoma of the breast. Pathol Int 1994, 44:874-877.

15. Sarela Al, Madvanur AA, Soonawala ZF, Shah HK, Pandit AA, Samsi AB: Carcinoma in a fibroadenoma. J Postgrad Med 1995, 41:19-20.

16. Shah AK, Pathak R, Banerjee SN, Kaul A, Niazi M, Girishkumar HT: Lobular carcinoma-in-situ within a fibroadenoma of the breast. Postgrad Med $J$ 1999, 75:293-294.

17. Yano $Y$, Ueno E, Kamma H, Tsunoda H, Hara H, Yashiro T, Alyoshi Y, Wu W, Hukazawa M: Non-invasive lobular carcinoma within a fibroadenoma, a preoperatively diagnosed case. Breast Cancer 2001, 8:70-73.

18. Kuijper A, Preisler-Adams SS, Rahusen FD, Gille JJP, van der Wall E, van Diest $P J:$ Multiple fibroadenomas harbouring carcinoma in situ in a woman 
with a family history of breast/ovarian cancer. J Clin Pathol 2002, 55:795-797.

19. Abe H, Hanasawa K, Naitoh H, Endo Y, Tani T, Kushima R: Invasive ducta carcinoma within a fibroadenoma of the breast. Int J Clin Oncol 2004 , 9:334-338.

20. Stafyla V, Kotsifopoulos N, Grigoriades K, Kassaras G, Sakorafas GH: Lobular carcinoma in situ of the breast within a fibroadenoma: a case report. Gynecol Oncol 2004, 94:572-574.

21. Shin JH, Choi HY, Lee SN, Kim YJ: Microinvasive ductal carcinoma arising within a fibroadenoma: a case report. Acta Radiol 2006, 47:643-645.

22. Yuen S, Uematsu T, Kasami M: Two cases of small infiltrating lobular carcinomas mimicking fibroadenoma on breast MRI. Breast J 2007, 13:616-617.

23. Borecky N, Rickard M: Preoperative diagnosis of carcinoma within fibroadenoma on screening mammograms. J Med Imaging Radiat Oncol 2008, 52:64-67.

24. Gashi-Luci LH, Limani RA, Kurshumliu Fl: Invasive ductal carcinoma within fibroadenoma: a case report. Cases J 2009, 2:174.

25. Khandelwal CR, Tandon M, Yashwant K, Kulshreshtha P, Aeron T, Bhatnaga D, Bansal A, Saxena S: Carcinoma developing in a fibroadenoma in a woman with a family history of breast cancer: a case report and review of literature. Cases J 2009, 2:9348.

26. lyengar KR, Peh SC, Yip CH, Vijayananthan A: Infiltrating duct carcinoma within a fibroadenoma. Indian J Cancer 2009, 46:244-246.

27. Rao S, Latha S, Ravi A, Thanka J: Ductal carcinoma in a multiple fibroadenoma: diagnostic inaccuracies. J Cancer Res Ther 2010, 6:385-387.

28. Petersson F, Tan PH, Putti TC: Low-grade ductal carcinoma in situ and invasive mammary carcinoma with columnar cell morphology arising in a complex fibroadenoma in continuity with columnar cell change and flat epithelial atypia. Int J Surg Pathol 2010, 18:352-357.

29. Kato F, Omatsu T, Matsumura W, Takahashi M, Hosoda M, Takahashi H, Kubota K, Oyama-Manabe N, Terae S, Shirato H: Dynamic MR findings of ductal carcinoma in situ within a fibroadenoma. Magn Reson Med Sci 2011, 10:129-132.

30. Ooe A, Takahara S, Sumiyoshi K, Yamamoto H, Shiba E, Kawai J: Preoperative diagnosis of ductal carcinoma in situ arising within a mammary fibroadenoma: a case report. Jpn J Clin Oncol 2011, 41:918-923.

31. Tajima S, Kanemaki Y, Kurihara Y, Okamoto K, Shimamoto H, Okazaki H, Okuda I, Kawahara F, Nakajima Y, Fukuda M, Maeda I: A case of a fibroadenoma coexisting with an invasive lobular carcinoma in the breast. Breast Cancer 2011, 18:319-323.

32. Abu-Rahmeh Z, Nseir W, Naroditzky I: Invasive ductal carcinoma within fibroadenoma and lung metastases. Int J Gen Med 2012, 5:19-21.

33. Jahan F, Ghosh PK, Rahman S, Khanam R: Fibroadenoma with foci of infiltrating ductal carcinoma. JOM J Medicine 2012, 13:115-117.

34. Butler R, Pinsky R, Jorns JM: Alveolar variant of invasive lobular carcinoma in a fibroadenoma. Breast J 2012, 18:613-614.

35. Kuijper A, Mommers EC, van der Wall E, van Diest PJ: Histopathology of fibroadenoma of the breast. Am J Clin Pathol 2001, 115:736-742.

36. Farrow DC, Hunt WC, Samet JM: Geographic variation in the treatment of localized breast cancer. N Engl J Med 1992, 326:1097-1101.

37. Bland Kl, Menck HR, Scott-Conner CE, Morrow M, Winchester DJ, Winchester DP: The National Cancer Data Base 10-year survey of breast carcinoma treatment at hospitals in the United States. Cancer 1998, 83:1262-1273.

38. Rosen PP, Kosloff C, Lieberman PH, Adair F, Braun DW Jr: Lobular carcinoma in situ of the breast: detailed analysis of 99 patients with average follow-up of 24 years. Am J Surg Pathol 1978, 2:225-251.

39. Yoshida $Y$, Takaoka M, Fukumoto M: Carcinoma arising in fibroadenoma: case report and review of the world literature. J Surg Oncol 1985, 29:132-140.

40. Fisher B, Anderson S, Bryant J, Margolese RG, Deutsch M, Fisher ER, Jeong $\mathrm{JH}$, Wolmark N: Twenty-year follow-up of a randomized trial comparing total mastectomy, lumpectomy, and lumpectomy plus irradiation for the treatment of invasive breast cancer. N Engl J Med 2002, 347:1233-1241.

41. Tiu CM, Chou YH, Chiou SY, Hsu CY, Chen SP, Chiang HR, Lai CR, Tseng LM, Wang HK, Chiou HJ: Development of a carcinoma in situ in a fibroadenoma: color Doppler sonographic demonstration. J Ultrasound Med 2006, 25:1335-1338.

42. Sastre-Garau X, Jouve M, Asselain B, Vincent-Salomon A, Beuzeboc P, Dorval T, Durand JC, Fourquet A, Pouillart P: Infiltrating lobular carcinoma of the breast: clinicopathologic analysis of 975 cases with reference to data on conservative therapy and metastatic patterns. Cancer 1996, 77:113-120.

43. Zafrani $B$, Aubriot MH, Mouret $E$, De Crémoux $P$, De Rycke $Y$, Nicolas A Boudou E, Vincent-Salomon A, Magdelénat H, Sastre-Garau X: High sensitivity and specificity of immunohistochemistry for the detection of hormone receptors in breast carcinoma: comparison with biochemical determination in a prospective study of 793 cases. Histopathology 2000, 37:536-545.

44. Kaptain S, Tan LK, Chen B: Her-2/neu and breast cancer. Diagn Mol Pathol 2001, 10:139-152.

45. Bundred NJ: Prognostic and predictive factors in breast cancer. Cancer Treat Rev 2001, 27:137-142.

46. Ravdin PM, Chamness GC: The c-erbB-2 proto-oncogene as a prognostic and predictive marker in breast cancer: a paradigm for the development of other macromolecular markers-a review. Gene 1995, 159:19-27.

47. Harrington SW, Miller JM: Malignant changes in fibroadenoma of the mammary gland. Surg Gynecol Obstet 1940, 70:615-619.

48. Morimoto T, Tanaka T, Komaki K, Sasa M, Monden Y, Kumagai H, Otsuka H: The coexistence of lobular carcinoma in a fibroadenoma with a malignant phyllodes tumor in the opposite breast: report of a case. Surg Today 1993, 23:656-660.

49. Ben Hassouna J, Damak T, Ben Slama A, Chargui R, Ben Dhiab T, Khomsi F, Gamoud A, Boussen H, Rahal K: Breast carcinoma arising within fibroadenomas: report of four observations. Tunis Med 2007, 85:891-895.

50. Pick PW, lossifides IA: Occurrence of breast carcinoma within a fibroadenoma: a review. Arch Pathol Lab Med 1984, 108:590-594.

51. Diaz NM, Palmer JO, McDivitt RW: Carcinoma arising within fibroadenomas of the breast: a clinicopathologic study of 105 patients. Am J Clin Pathol 1991, 95:614-622.

\section{doi:10.1186/1477-7819-12-335}

Cite this article as: Wu et al:: Breast cancer arising within fibroadenoma: collective analysis of case reports in the literature and hints on treatment policy. World Journal of Surgical Oncology 2014 12:335.

\section{Submit your next manuscript to BioMed Central and take full advantage of:}

- Convenient online submission

- Thorough peer review

- No space constraints or color figure charges

- Immediate publication on acceptance

- Inclusion in PubMed, CAS, Scopus and Google Scholar

- Research which is freely available for redistribution
C Biomed Central 